Journal of The Magnetics Society of Japan Vol. 13, Supplement, No. S1 (1989)

(C) 1989 by The Magnetics Society of Japan

\title{
STRUCTURAL INHOMOGENEITIES IN Co-Cr LAYERS AND THEIR INFLUENCE ON THE MAGNETIC PROPERTIES
}

\author{
C.P.G. SCHRAUWEN, J.P.C. BERNARDS \\ Philips Research Laboratories, P.O. Box 80.000 , \\ $5600 \mathrm{JA}$ Eindhoven, The Netherlands.
}

\begin{abstract}
Structural inhomogeneities are observed in $\mathrm{RF}$ sputtered $\mathrm{Co}_{79} \mathrm{Cr}_{21}$ layers, studied for perpendicular magnetic recording. The effective perpendicular anisotropy is strongly affected by the occurrence of inhomogeneities in the growth direction (e.g. an initial layer), which can be diminished by changing the substrate or by using a Ge underlayer. Lateral inhomogeneities (e.g. due to segregation) have a large impact on the coercivity of the layers and are strongly affected by the substrate temperature during deposition. The substrate temperature is observed to increase steeply at the start of the deposition $\left(20-40^{\circ} \mathrm{C}\right)$. This increase depends on the sputtering power. The further evolution of temperature is dominated by the substrate holder. The thermal contact between substrate and holder can be established reproducibly.
\end{abstract}

\section{INTRODUCTION}

Co-Cr containing recording media are currently investigated because of their potential use in high density recording. Using single layered (SL) media and ring heads, recording densities up to 1 $\mathrm{bit} / \mu \mathrm{m}^{2}$ are obtainable now $[1,2]$. More knowledge on the magnetic properties, their relation with and dependence on the structural properties, and the structural properties themselves may result in a better understanding of the recording process and may show ways to even higher densities. In this paper we shall focus on the influence of the substrate temperature during deposition and of the substrate itself on the structural and magnetic properties of the $\mathrm{Co}-\mathrm{Cr}$ layer.

\section{EXPERIMENTAL CONDITIONS}

$\mathrm{CO}_{79} \mathrm{Cr}_{21}$ and $\mathrm{Ge}$ layers are $\mathrm{RF}$-sputtered from 8" targets on flexible $14.5 \mu \mathrm{m}$ thick polyester (PE) or $12.5 \mu \mathrm{m}$ thick polyimide (PI) substrates. The Co-Cr target is an alloy. The spacing between target and substrate is $5 \mathrm{~cm}$. The substrates $\left(150 \mathrm{~cm}^{2}\right)$, held in metal rings, are loaded into the vacuum using a load-lock and stored there about $15 \mathrm{~min}$. prior to the deposition in order to reach a constant background pressure level of about $70 \mathrm{mPa}$ (mainly $\mathrm{H}_{2} \mathrm{O}$ and/or $\mathrm{H}_{2}$ ). Preceding depositions at elevated temperatures, the substrates are preheated in an oven under atmospheric pressure in the presence of a drying agent before loading. No further substrate pretreatments are applied. The sputtering gas is argon $(1.3 \mathrm{~Pa})$. The deposition rate is about $35 \mathrm{~nm} / \mathrm{min}$ for Ge $(200$ $\mathrm{W}$ deposition power) and $40 \mathrm{~nm} / \mathrm{min}(600 \mathrm{~W})$ or 25 $\mathrm{nm} / \mathrm{min}(300 \mathrm{~W})$ for $\mathrm{Co}-\mathrm{Cr}$. The $\mathrm{Ge}$ underlayer is 0 to $400 \mathrm{~nm}$, the Co-Cr layer is 10 to $800 \mathrm{~nm}$ thick.

The substrates are stretched on a metal holder to ensure good contact with the holder surface to prevent heat damage during sputter deposition. Holder $\Lambda$ is a $2.5 \mathrm{~kg}$ stainless steel body, which is optionally heated prior to the deposition using heater lamps on the side opposite to the substrate. It will also heat up due to accumulation of the power input during sputtering because it lacks a cooling facility. Holder $B$ is equipped with a channel just under the holder surface through which a liquid flows, which is held at a fixed temperature, thus enabling heating of the substrate prior to and cooling of the substrate during the deposition. Cross-sections are schematically shown in Fig. 1.

Temperature measurements are performed using Luxtron 750 fluoroptic temperature measuring equipment [3]. This system is based on the temperature dependence of the intensities of the fluorescent emission lines from a rare earth phosphor sensor attached to the end of an optical fiber probe. As the temperature measurement is not electrical, unlike e.g. a thermo-couple, it remains undisturbed by the $\mathrm{RF}$-fields and temperature can be measured easily during the deposition. The probe tip, about $1 \mathrm{~mm}$ across, is closely contacted to the flexible substrate using a heat-conductive paste. Some caution when interpreting the temperatures measured is necessary, because of the large differences in size between the probe tip with conducting paste and the substrate itself.

Hysteresis loops are measured with a VSM to obtain the perpendicular coercivity $\left(\mathrm{H}_{\mathrm{c}}^{\perp}\right)$ and the saturation magnetisation $M_{s}$, which is is observed to be about $420 \mathrm{kA} / \mathrm{m}$. $\Lambda$ torque magnetometer is used to measure the magnetic anisotropy. $K_{\text {err }}$ is used as a figure of merit, being the net volume energy difference between the perpendicular and the in-plane oriented magnetised situations as determined from the torque curve. For a homogeneous uniaxial layer $\mathrm{K}_{\text {ef }}$ is equal to $K_{u}-1 / 2 \mu_{0} M_{s}^{2}$, where $K_{u}$ is the uniaxial crystalline anisotropy. The demagnetisation energy $1 / 2 \mu_{0} \mathrm{M}_{\mathrm{s}}^{2}$ is about $110 \mathrm{~kJ} / \mathrm{m}^{3}$.

$\mathrm{X}$-ray diffraction is used to characterize the texture of the film and the spread in the c-axis $\left(\Delta \theta_{s 0}\right)$. The microstructure of the film is studied by TEM, using layer cross-sections and planar sections. Crosssections are obtained by slicing media held between Si wafers, polishing with diamond powder to a thickness of about $30 \mu \mathrm{m}$ and further thinning by ion-milling. Planar sections are obtained by dissolv- 
ing the substrate followed by ion milling from the former substrate side. Both bright-field micrographs and electron difraction patterns are obtained.

\section{RESULTS}

\section{Substrate temperature}

The evolution of the substrate temperature during the sputter-deposition of $\mathrm{Co}-\mathrm{Cr}$ on the substrate has been studied. 'Two typical curves, obtained for PE substrates are shown in fig. 1 , one on holder $A$, the other on holder $B$.

$\Lambda t$ the start of the deposition (deposition time $=0$ ), a sudden rise in temperature is observed. This rise is due to the heating of the substrate by the plasma and is dependent on the applied sputtering power as can be seen in fig. 1 comparing $\Lambda$ and $B$. In the first few minutes fluctuations are observed, which are most probably caused by changes in the heat contact between substrate and holder. This is due to expansion of the metal ring around the substrate which is heated by the plasma. Also, the heat influences the dimensions of the flexible PE substrate itself, but its behavior is more complicated. Firstly it will expand due to the heating, but as it has been stretched in the production process, it will soon start to shrink. $\Lambda$ fter some time, the temperature on holder $A$ is rising steadily, because the holder body is heated up and no active cooling takes place. The temperature of holder $B$ is actively controlled, so the temperature reaches a constant value. From the fact, that this tcmperature level on holder $B$ is well above the tem-

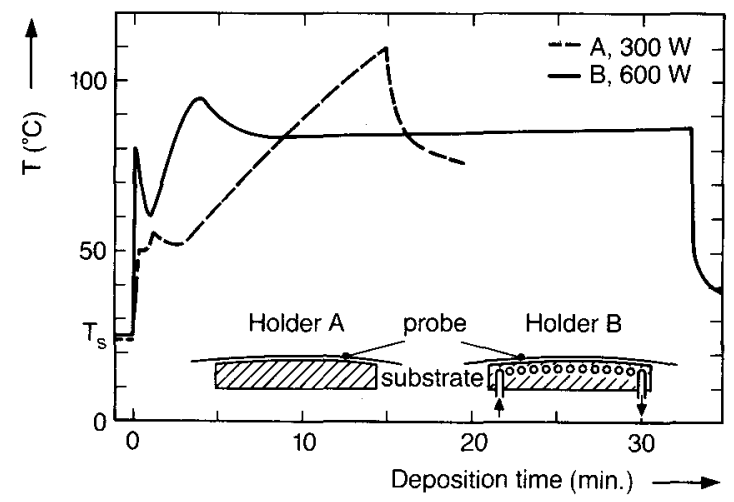

FIG. 1. Temperature evolution during deposition of $\mathrm{Co}-\mathrm{Cr}$. Dashed line: depositing $375 \mathrm{~nm}$ of $\mathrm{Co}-\mathrm{Cr}$ using holder $\Lambda$ at a power of $300 \mathrm{~W}$. Solid line: depositing $1.3 \mu \mathrm{m}$ of $\mathrm{Co}-\mathrm{Cr}$ using holder $\mathrm{B}$ at $600 \mathrm{~W}$. Inserts: cross-sections of $\mathrm{A}$ and $\mathrm{B}$, depicting the shape of their surface, the substrate stretched over them, and the position of the measuring probe. perature at the start of the deposition $\left(\mathrm{T}_{s}\right)$ and from the slow decrease observed after the deposition has stopped, it is clear that the main heat resistance is between the flexible substrate and the holder surface. There exists virtually no temperature difference betwcen both sides of the substrate. It is easily calculated from simple models for heat flow in bodies that within $2.3 \mathrm{~ms}$ the temperature difference between the two sides of the substrate is less than $10 \%$ of the difference between $T_{s}$ and the temperature of the upper side during deposition. The thermal diffusivity of $\mathrm{PE}$ or PI is typical $83.10^{-9} \mathrm{~m}^{2} / \mathrm{s}$. The heat resistance can be lowered by putting vacuum grease or heat conducting paste between substrate and holder. In that case the temperature step at the beginning of the deposition disappears.

The shape of the temperature curves is reproducible, also when $P I$ is used or when $T_{s}$ is raised. At the start the same temperature jump occurs, and the temperature slowly increases on holder $A$, while it levels off on holder $B$. At $\mathrm{T}_{s}$-values above about 100 ${ }^{\circ} \mathrm{C}$ the fluctuations in the first few minutes are no longer observed. The slope of the gradual temperature increase on holder $\Lambda$ diminishes at higher values for $\mathrm{T}_{s}$. This is due to the fact, that the holder is only preheated before the deposition, while there is no additional heating during the actual deposition, except for the heating by the plasma.

When the substrate is clamped reproducibly on the holder, the temperature profile is reproduced, apart from the exact shape of the fluctuations in the beginning. Thus the temperature at the start of the deposition $\left(T_{s}\right)$ which is the same as the temperature of the liquid for holder B and which is easily obtained, can be used to rank samples according to deposition temperature. Only when the substrate is installed differently, or other or more layers are used, the actual temperature profile may well change.

The substrate temperature is observed to mainly influence the $\mathrm{H}_{c}^{\frac{1}{c}}$. Fig. 2 shows the change in $\mathrm{H}_{c}^{\frac{1}{c}}$ with $\mathrm{T}_{s}$. One set of data is from $200 \mathrm{~nm}$ thick $\mathrm{Co}-\mathrm{Cr}$ samples, (holder $A$ ), and the other set from $400 \mathrm{~nm}$ thick Co-Cr samples (holder B). In both cases the sputtering power is $600 \mathrm{~W}$. At low temperatures, the $200 \mathrm{~nm}$ thick layers have a higher coercivity than the $400 \mathrm{~nm}$ thick layers. This is easily understood from the curves shown in fig. 1 . In both cases, the temperature jump at the start of the deposition is the same. Then, the samples on holder A will slowly increase in temperature, while those on holder B will remain at the same temperature level, causing the temperature during deposition to be higher for the first. At higher temperature, this difference will become smaller as holder $A$ will loose more heat to the surroundings, It is suggested by Werner et al. [4] that $H_{c}^{\perp}$ depends on the mean temperature during deposition. 


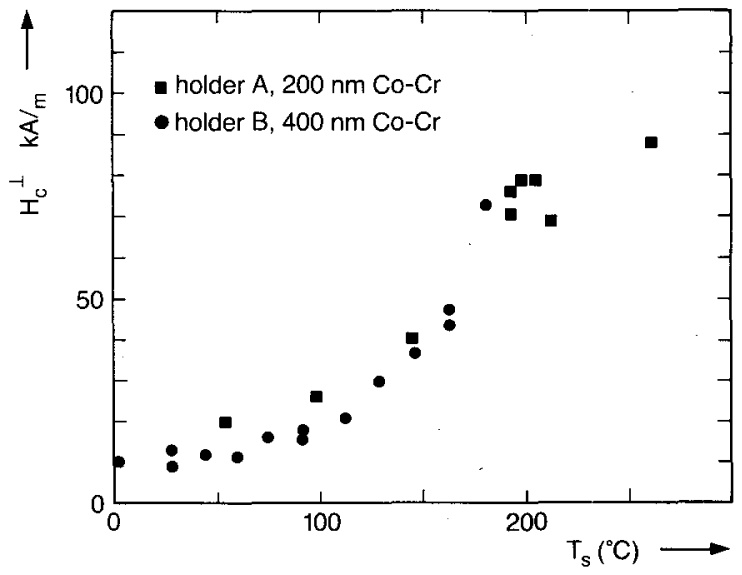

FIG. 2. The dependence of $H_{c}^{\perp}$ on $T_{s}$. Squares: 200 $\mathrm{nm}$ thick Co-Cr layers, deposited using holder $A$, dots: $400 \mathrm{~nm}$ thick Co-Cr layers, deposited using holder B. All results on $400 \mathrm{~nm}$ thick Ge underlayers and at a sputtering power of $600 \mathrm{~W}$.

\section{$\mathrm{Co}-\mathrm{Cr}$ on polymer substrates}

Co-Cr layers deposited directly on the substrate at high $\mathrm{T}_{\mathrm{s}}\left(\geq 90^{\circ} \mathrm{C}\right)$ often exhibit an inhomogeneous structural growth. The initial layer does not have a well-defined columnar structure [5]. An example of this is given in fig. $3 \mathrm{a}$, which shows part of a crosssection of a $400 \mathrm{~nm}$ thick Co-Cr layer deposited directly on $\mathrm{PE}$ at a $\mathrm{T}_{\mathrm{s}}$ of $90^{\circ} \mathrm{C}$ on holder $\mathrm{A}$. The diffraction pattern is taken from the first $50 \mathrm{~nm}$ of the layer. This initial layer has no preferential orientation and therefore its effective anisotropy is negative and its magnetisation lies in the plane of the layer. Such an initial layer has also been observed by other authors $[6,7]$. When the layer thickness increases a columnar structure develops, $\Delta \theta_{50}$ diminishes and $K_{\text {eff }}$ increases. This can be scen in table I in which the properties of a $200 \mathrm{~nm}$ and a $800 \mathrm{~nm}$ thick layer are compared (samples 1 and 2). The inhomogeneous structural growth results in a strong dependence of $\mathrm{H}_{c}^{\perp}$ on the layer thickness, as is shown in fig. 4. The initial layer has a low $H_{c}^{\perp}$, but with the development of the columns $\mathrm{H}_{\mathrm{c}}^{+}$increases.

The columnar structure in layers deposited at low $\mathrm{T}_{\text {s }}$ (about $30^{\circ} \mathrm{C}$ ) starts to develop sooner, as can be scen in fig. $3 b$. The diffraction pattern, again taken from the first $50 \mathrm{~nm}$ of the layer, shows that the initial layer has a preferential orientation with the caxis perpendicular to the substrate. With increasing thickness the properties of the layers do not change to such a large extent (samples 3 and 4 , table I) as the properties of the layers deposited at a $T_{s}$ of 90 ${ }^{\circ} \mathrm{C}$. In particular the coercivity is not dependent on the layer thickness; $\mathrm{H}_{\mathrm{c}}^{\perp}$ is about $15 \mathrm{kA} / \mathrm{m}$ for all layer thicknesses (fig. 4), except for the $10 \mathrm{~nm}$ thick layer,

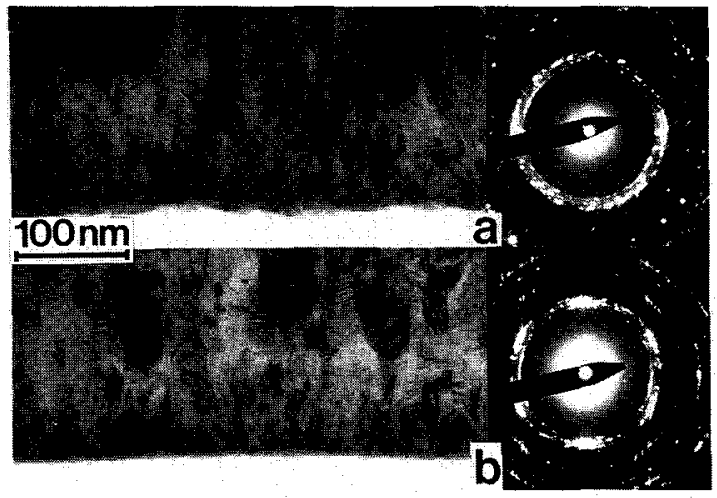

FIG. 3 Parts of cross-sections through 400 nm thick Co-Cr layers deposited directly on the substrate. a: $\mathrm{T}_{\mathrm{s}}=90^{\circ} \mathrm{C}, \mathrm{b}: \mathrm{T}_{\mathrm{s}}=30^{\circ} \mathrm{C}$. The diffraction patterns are taken from the lower $50 \mathrm{~nm}$.

which has a $\mathrm{H}_{c}^{\perp}$ of half this value. Thus, the layers deposited at a $\mathrm{T}_{\mathrm{s}}$ of $30^{\circ} \mathrm{C}$ are more homogeneous in the growth direction than those deposited at a $\mathrm{T}_{\mathrm{s}}$ of $90^{\circ} \mathrm{C}$. In layers deposited directly on the polymer substrate a dependence of the $\mathrm{Cr}$ segregation on the substrate temperature has been observed in the part of the layers with the well-defined columnar structure [8]. In layers deposited at a $T_{s}$ of $30^{\circ} \mathrm{C}$ no segregation is observed while in layers deposited at a $\mathrm{T}_{s}$ of $90^{\circ} \mathrm{C}$ the $\mathrm{Cr}$ content in the boundaries is about 6 at. $\%$ higher than in the columns.

\begin{tabular}{|c|c|c|c|c|c|c|c|c|}
\hline no. & sh & $\begin{array}{c}\mathrm{d}_{\mathrm{CoCr}} \\
\mathrm{nm}\end{array}$ & $\begin{array}{c}\mathrm{T}_{s} \\
{ }^{\circ} \mathrm{C}\end{array}$ & $s$ & $\begin{array}{c}\mathrm{d}_{\mathrm{Ge}} \\
\mathrm{nm}\end{array}$ & $\begin{array}{c}H_{\mathrm{H}}^{\frac{1}{c}} \\
\mathrm{k} \wedge / \mathrm{m}\end{array}$ & $\underset{\mathrm{kJ} / \mathrm{m}^{3}}{\mathrm{~K}_{\text {eff }}}$ & $\Delta \theta_{50}$ \\
\hline 1 & $\Lambda$ & 200 & 90 & $\mathrm{PE}$ & 0 & 55 & -110 & 14.5 \\
\hline 2 & $\mathrm{~A}$ & 800 & 90 & $\mathrm{PE}$ & 0 & 61 & 10 & 7.5 \\
\hline 3 & $A$ & 200 & 30 & $\mathrm{PE}$ & 0 & 15 & -16 & 6.8 \\
\hline 4 & $A$ & 800 & 30 & $\mathrm{PE}$ & 0 & 17 & -2 & 7.1 \\
\hline 5 & $\Lambda$ & 10 & 30 & $\mathrm{PE}$ & 400 & 2 & 26 & 9.0 \\
\hline 6 & $A$ & 200 & 30 & $\mathrm{PE}$ & 400 & 25 & 16 & 8.5 \\
\hline 7 & $\Lambda$ & 800 & 30 & $\mathrm{PE}$ & 400 & 27 & 31 & 6.0 \\
\hline 8 & $B$ & 200 & 160 & PI & 400 & 45 & 16 & 4.2 \\
\hline 9 & $B$ & 800 & 160 & $\mathrm{PI}$ & 400 & 46 & 30 & 3.3 \\
\hline 10 & $A$ & 200 & 100 & PI & 400 & 26 & 25 & 3.1 \\
\hline 11 & $\Lambda$ & 200 & 210 & PI & 400 & 70 & 23 & 3.7 \\
\hline 12 & $B$ & 200 & 30 & $\mathrm{PE}$ & 50 & 37 & 9 & 7.6 \\
\hline 13 & B & 200 & 30 & & 50 & 8 & 23 & 3.4 \\
\hline
\end{tabular}

Table 1: Some of the properties of Co-Cr layers deposited under various conditions. The substrate (s) is PE, PI, or xylene washed polyester $\left(^{*}\right)$. The substrate holder (sh) is A or B. 
Co-Cr with $\mathrm{Ge}$ underlayer

$\mathrm{Co}-\mathrm{Cr}$ layers deposited on an amorphous $\mathrm{Ge}$ underlayer have a high $K_{\text {eff }}[9,10]$, higher than when deposited directly on PE, as can be seen in table I. Even layers as thin as $10 \mathrm{~nm}$ have a positive $K_{\mathrm{err}}$ (Table 1, sample 5). This is caused by a better crystallographic orientation of the initial layer and therefore of the total layer. $\Delta \theta_{s 0}$ of a $10 \mathrm{~nm}$ thick layer deposited directly on the substrate is too high to be measured with our equipment, while such a thin layer on Ge has already a $\Delta \theta_{50}$ comparable to the value of a 10 times thicker layer deposited directly on the substrate.

The $H_{c}^{\perp}$ of layers deposited on $\mathrm{Ge}$ at a $T_{s}$ of 30 ${ }^{\circ} \mathrm{C}$ is somewhat higher than for the layers deposited directly on $P E$ at the same $T_{s}$, most probably due to the temperature increase of holder $\mathrm{A}$ during Ge deposition, but the coercivities are still rather low. Again $\mathrm{H}_{c}^{\perp}$ does not change much with increasing layer thickness (fig. 4); $\mathrm{H}_{c}^{\perp}$ is about $24 \mathrm{kA} / \mathrm{m}$, except for the thinnest layer.

$\mathrm{H}_{c}^{\perp}$ of layers deposited at a $\mathrm{T}_{\mathrm{s}}$ of $160^{\circ} \mathrm{C}$ is about $46 \mathrm{kA} / \mathrm{m}$, again more or less independent of the layer thickness (fig. 4). This indicates that at high substrate temperatures, layers deposited on Ge underlayers are homogeneous in the growth direction too.

However, in the lateral direction inhomogeneities

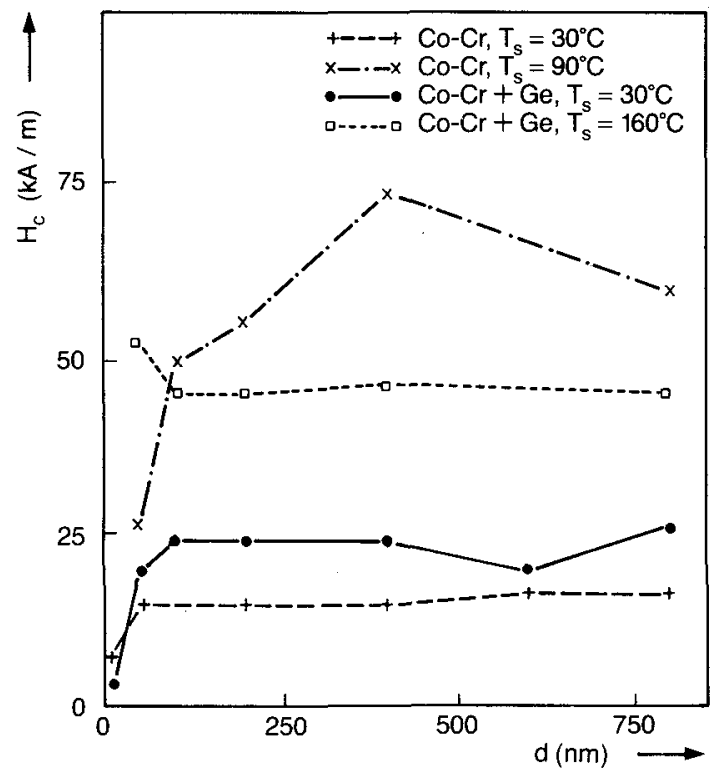

FIG. $4 \mathrm{H}_{\mathrm{c}}^{\perp}$ against the $\mathrm{Co}-\mathrm{Cr}$ layer thickness $\mathrm{d}$ for layers deposited $(600 \mathrm{~W})$ at low and high $T_{s}$, with and without $\mathrm{Ge}$ underlayer. All on holder $\mathrm{A}$ except for the $\mathrm{Co}-\mathrm{Cr}+\mathrm{Ge}$ at high $\mathrm{T}_{5}$.
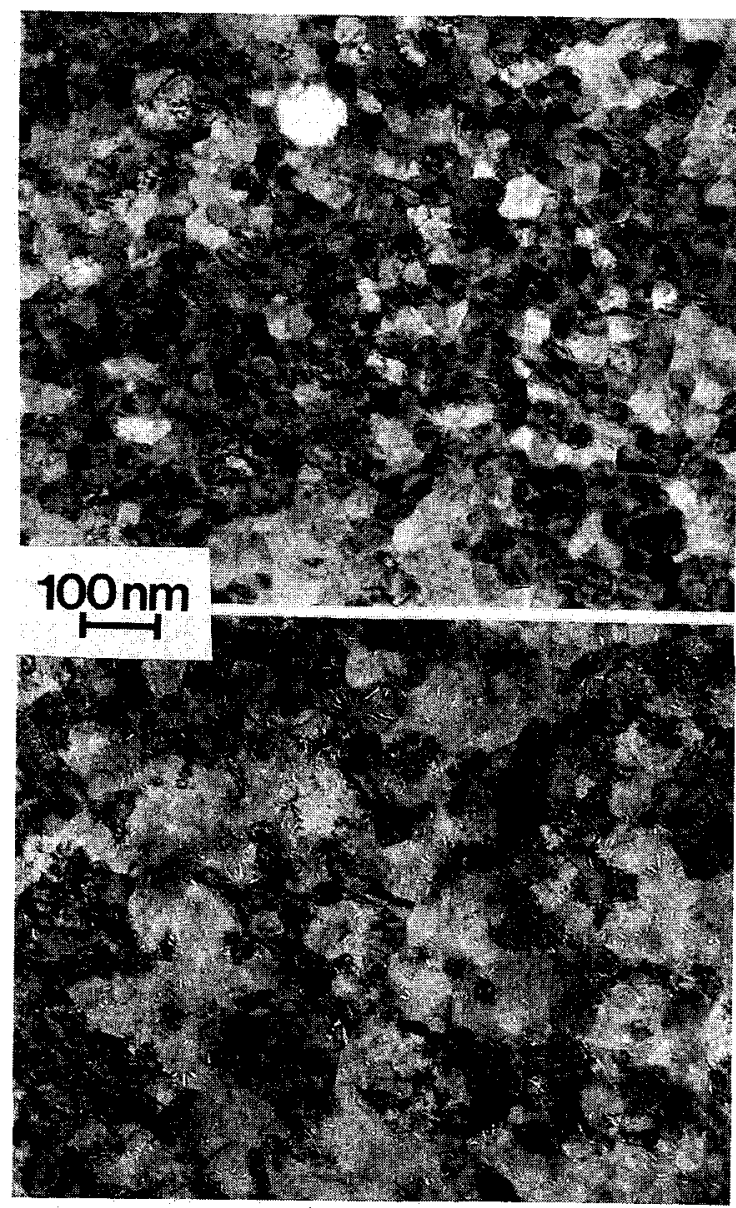

FIG. 5 Planar sections of Co-Cr layers 10 (top) and 11 (bottom) (Table 1).

exist. FMR spectra, measured with the applied field in the perpendicular direction, exhibit two peaks, both with perpendicular anisotropy, which are attributed to lateral magnetic inhomogeneities [11]. Structural inhomogeneities can be seen in fig. 5. This figure shows TEM micrographs of planar sections from layer 10 and layer 11 (Table 1). It seems that the columns in layer 11 are larger than the columns in layer 10 but it is diflicult to see where the column boundaries are located. In layer 11 small stripes (about $10 \mathrm{~nm}$ long) are observed.

\section{Substrate influence}

From the previous two sections it is clear that the substrate has an influence on the structure and properties of the $\mathrm{Co}-\mathrm{Cr}$ layer. The influence of the substrate can be eliminated and the $\mathrm{Co}-\mathrm{Cr}$ properties 


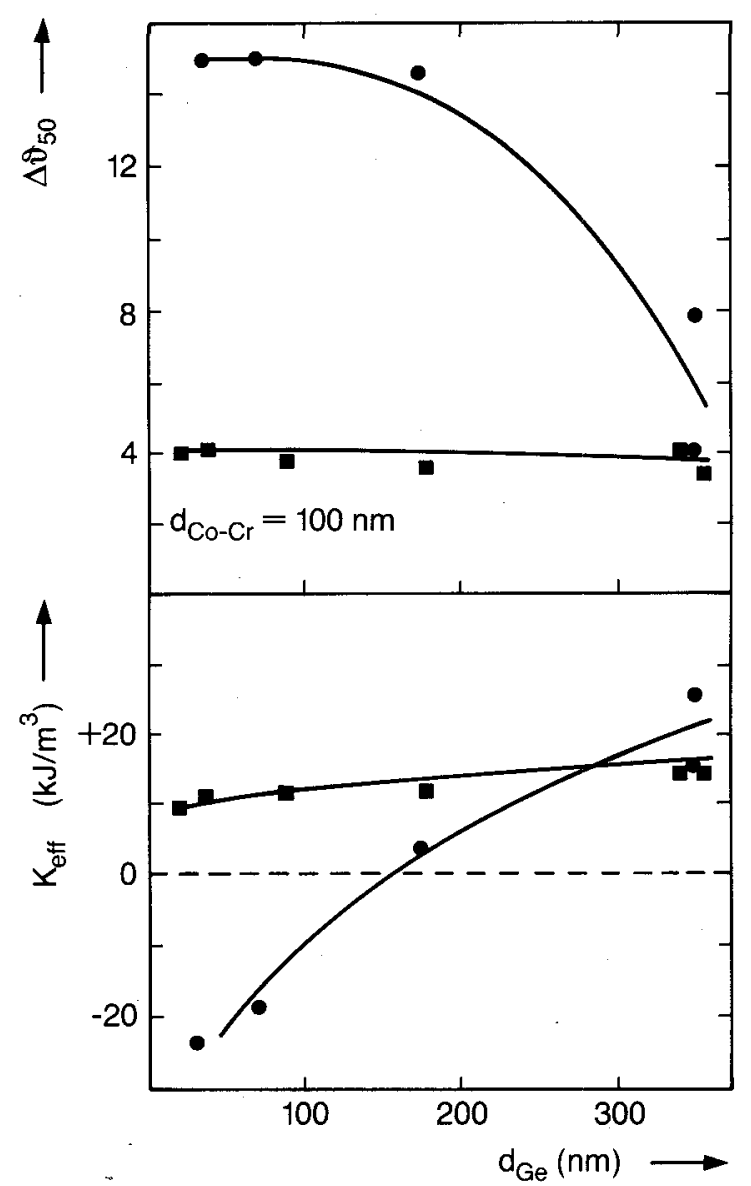

FIG. 6. $\Delta \theta_{50}$ and $K_{\text {efr }}$ as a function of the Ge thickness. Dots : PE data from [10], squares : PI data. The Co-Cr layer thickness is $100 \mathrm{~nm}$.

improved using a Ge underlayer. We have shown on a previous occasion [10], that first the PE has to be covered with Ge layer of a thickness larger than 200 to $250 \mathrm{~nm}$ to seal off impurities before the full effect of the Ge underlayer is exerted. Fig. 6 shows these results again, but now the results obtained using $\mathrm{Pl}$ are shown, too. The effect of the Ge underlayer is only small on PI, and even no Ge may give a low $\Delta \theta_{50}$ and a positive $K_{\text {err. }}$. The values for $\mathrm{K}_{\text {eff }}$ and $\Delta \theta_{50}$ are not significantly different between using PE or PI when a thick Ge underlayer is applied. On PI as on PE, an increase in Co-Cr layer thickness has the same effect: $\Delta \theta_{50}$ decreases and $\mathrm{K}_{\mathrm{err}}$ increases (Table 1 ).
The influence of the impurities coming from the PE can be diminished by pretreatment of the substrate. When treated with a boiling solvent, e.g. xylene, the properties of a Co-Cr layer on a $50 \mathrm{~nm}$ thick Ge underlayer are improved (Table 1, sample 12 and 13). Still, it is not possible to use this treated PE without a $\mathrm{Ge}$ underlayer. The influence of the PE and the nature of the impurities have to be investigated further. On PI, the impurity level seems to be much lower.

The reason for the improvement obtained on $\mathrm{Ge}$ underlayers, apart from the sealing from impurities, is not yet clear. The amorphous character of the $\mathrm{Ge}$ layer is important, as it is observed that the increase in $\mathrm{K}_{\text {eff }}$ of $\mathrm{Co}-\mathrm{Cr}$ on crystalline $\mathrm{Ge}$ samples $(<100>$, $\langle 110\rangle$ and $\langle 111\rangle$ ) is less than that of $\mathrm{Co}-\mathrm{Cr}$ on the sputtered, amorphous material. It can be calculated, that the best match could appear between $\mathrm{Ge}$ $\langle 111\rangle$ and $\mathrm{Co}-\mathrm{Cr}<0001\rangle$. In the experiment, this sample has the lowest $K_{\text {eff }}$ and the highest $\Delta \theta_{5 n}$ of the possibilities examined. We presume therefore, that Ge offers a non-contaminated, non-structured surface on which $\mathrm{Co}-\mathrm{Cr}$ is free to nucleate with its preferred orientation.

\section{DISCUSSION}

Evidence for the existence of inhomogeneities in $\mathrm{Co}-\mathrm{Cr}$ both in the growth direction and in the lateral direction has been presented. Similar observations have been reported for double-layered recording media [12].

Inhomogeneities in the growth direction reduce $\mathrm{K}_{\mathrm{er}}$ and augment $\Delta \theta_{50}$, and are induced by the substrate. Impurities originating from the substrate or the structurc of the substrate influence the appearance of these inhomogeneities. An amorphous $\mathrm{Ge}$ underlayer probably provides a clean, nonstructured surface and $\mathrm{Co}-\mathrm{Cr}$ layers which are homogeneous in the growth direction can be deposited. On PI also fairly homogeneous layers can be deposited, but on PE, especially at high $\mathrm{T}_{s}, \Delta \theta_{s 0}$ is increased and $\mathrm{K}_{\mathrm{eff}}$ decreased, due to the appearance of inhomogeneities, e.g. the initial layer.

Lateral inhomogeneities increase $\mathrm{H}_{c}^{\frac{1}{c}}$, and are induced by the substrate temperature. These inhomogeneities may be ascribed to segregation efrects. The actual segregation that is observed seems to be influenced by the substrate. A clear segregation to the column boundary is reported for layers deposited directly on the substrate [8]. On Ge underlayers, the columnar structure is less clear, groups of columns with the same in-plane orientation are found [10] and structures are observed within the columns at higher substrate temperatures (fig. 5). The latter structures at some places resemble the chrysanthemum-like pattern structure reported by Maeda [13]. 
The inhomogeneities can act as pinning points for the movement of domain walls. In the case of $\mathrm{Cr}$ segregation towards the column boundaries the columns can become magnetically isolated from each other. Both mechanisms affect the coercivity and the switching behaviour of the layers. Layers with a low coercivity behave like continuous layers in which magnetisation reversal takes place by domain wall movement $[14-17]$. This behaviour can be described by the Kooy and Enz model [18]. Certain features of layers with a high coercivity can also be described by the Kooy and Enz model [16] , but there is also evidence that such layers have a more particulate character [17], which is consistent with the described segregation. One specially interesting feature observed in low coercivity layers with a high perpendicular anisotropy is the larger remanence and coercivity obtained when measuring minor hysteresis loops compared to the values obtained from the major hysteresis loop. This effect can be as large as $35 \%$ and can be explained by the stripe domain structure in these structurally homogeneous layers [19].. The decrease of this effect with increasing substrate temperature shows that the nature of these layers becomes less continuous with increasing $\mathrm{T}_{\mathrm{s}}$ and thus with decreasing homogeneity.

The observed changes in the structural homogeneity of the layers have a strong influence on the magnetic properties, and therefore on the recording properties too. Layers with a low coercivity show a high noise level because of their stripe domain structure. The noise level decreases with increasing coercivity [2], which is brought about by the decrease in lateral homogeneity due to an increased deposition temperature. Minima apart from the gap nulls are observed when a ring head is used to write on SL Co-Cr media [2]. This effect is observed to be caused by the write process, and depends on a.o. $K_{\text {err }}$ $[20,21]$. As shown above, $K_{\text {eff }}$ can be influenced by increasing the inhomogeneity in the growth direction.

\section{CONCLUSIONS}

The origins and influence of structural inhomogeneities in $\mathrm{Co}-\mathrm{Cr}$ layers for perpendicular recording media have been investigated.

The temperature during deposition of the $\mathrm{Co}-\mathrm{Cr}$ layer influences the lateral homogeneity, and causes the $\mathrm{H}_{\mathrm{c}}^{\perp}$ to increase with increasing temperature. Therefore, the temperature profile during the deposition of $\mathrm{Co}-\mathrm{Cr}$ has been studied. A fast increase in temperature of 20 to $40^{\circ} \mathrm{C}$ has been observed at the start of the deposition. After some minutes, the evolution of temperature is dominated by the substrate holder. The main heat resistance is always between substrate and holder.

The nature of the substrate, being PE, PI or a Gecovercd polymer influences the homogeneity in the growth direction. On amorphous $\mathrm{Ge}$ layers, $\mathrm{Co}-\mathrm{Cr}$ layers which are homogeneous in the growth direction are obtained. A high $\mathrm{K}_{\mathrm{err}}$ is observed, both at low and high substrate temperatures. When deposited directly on $\mathrm{PE}$, inhomogeneities in the growth direction of the $\mathrm{Co}-\mathrm{Cr}$ layer are observed at higher substrate temperatures. These inhomogeneities are due to impurities from the PE. These can be removed by solvent treatment, or excluded by using an underlayer which is sufficiently thick.

The occurrence of the structural changes has a strong influence on the magnetic properties of the layers, and hence on the recording properties of $\mathrm{Co}-\mathrm{Cr}$ layers for SL perpendicular magnetic recording media.

\section{REFERENCES}

[1] R. Sugita, T. Nambu, Y. Sakamoto; IEEE Trans. Magn. MAG-23, 1987, 2449

[2] S.B. Luitjens, R.W. de Bic, V. Zicren, J.P.C. Bernards, C.P.G. Schrauwen, H.A.J. Cramer; IEEE Trans. Magn. MAG-24, 1988, 2338

[3] Luxtron Fluoroptic Temperature Sensing, Mountain View, CA94043, USA;

[4] A. Werner, H. Hibst, E. Hädicke; Proc. 1st Int. Conf. on Plasma Surface Engeneering, Garmisch-Partenkirchen (1988)

[5] J.P.C. Bernards, C.P.G. Schrauwen, S.B. Luitjens, V. Zieren, R.W. de Bie; IEEE Trans. Magn. MAG-23, 1987, 125

[6] J.O. Artman; J. Appl. Phys, 61, 1987, 3137

[7] J.C. Lodder, C. Li; J. Magn. Magn. Mat. 74, 1988, 74

[8] D.J. Rogers, J.N. Chapman, J.P.C. Bernards, S. B. Luitjens; IEEE Trans. Magn., to be published (Intermag'89, Washington) [9] M. Futamoto, Y. Honda, H. Kakibayashi, K. Yoshida; IEEE Trans. Magn. MAG-21, 1985, 1426

[10] C.P.G. Schrauwen, J.P.C. Bernards, R.W. de Bie, G.J.P. van Engelen, H.H. Stel, V. Zieren, S.B. Luitjens; IEEE Trans. Magn. 24, 1988, 1901

[11] J.P.C. Bernards, C.P.G. Schrauwen, H.W. van Kesteren; IEEE Trans. Magn., to be published (MRM'89, Rimini)

[12] J.P.C. Bernards, C.P.G. Schrauwen, V. Zieren, S.B. Luitjens; J. Appl. Phys. 63, 1988, 2897

[13] Y. Maeda, M. Asahi; J. Appl. Phys. 61, (1987), 1972

[14] R.W. de Bie, S.B. Luitjens, V. Zieren, C.P.G. Schrauwen,

J.P.C. Bernards; IEEE Trans. Magn. MAG-23, 1987, 2091

[15] T. Wielinga; Thesis, University Twente, 1983

[16] J.P.C. Bernards, C.P.G. Schrauwen, S.B. Luitjens; Appl. Phys. A, accepted for publication

[17] K. Ouchi, S. Iwasaki; IEEE Trans. Magn. MAG-23, 1987 , 2443

[18] C. Kooy, U. Enz; Philips Res. Reports 15, 1960, 7

[19] J.P.C. Bernards, G.J.P. van Engelen, C.P.G. Schrauwen, H.H. Stel; J. Magn. Magn. Mat. 78, 1989, L119

[20] J.P.C. Bernards, G.J.P. van Engelen, C.P.G. Schrauwen, H.A.J. Cramer, S.B. Luitjens; IEEE Trans. Magn., to be published (MRM'89, Rimini)

[21] H.A.J. Cramer, C.P.G. Schrauwen, J.P.C. Bernards, S.B. Luitjens; IEEE Trans. Magn., to be published (MRM'89, Rimini) 